\title{
Article \\ Driver Cardiovascular Disease Detection Using Seismocardiogram
}

\author{
Gediminas Uskovas ${ }^{1}{ }^{\oplus}$, Algimantas Valinevicius ${ }^{1}$, Mindaugas Zilys ${ }^{1}$, Dangirutis Navikas ${ }^{1}$, \\ Michal Frivaldsky $\left.{ }^{2}{ }^{(}\right)$, Michal Prauzek ${ }^{3}{ }^{-}$, Jaromir Konecny ${ }^{3}{ }^{(1)}$ and Darius Andriukaitis $1, *(\mathbb{D})$
}

1 Department of Electronics Engineering, Kaunas University of Technology, Studentu St. 50-438, LT-51368 Kaunas, Lithuania; gediminas.uskovas@ktu.edu (G.U.); algimantas.valinevicius@ktu.lt (A.V.); mindaugas.zilys@ktu.lt (M.Z.); dangirutis.navikas@ktu.lt (D.N.)

2 Department of Mechatronics and Electronics, Faculty of Electrical Engineering and Information Technologies, University of Zilina, 01026 Zilina, Slovakia; michal.frivaldsky@fel.uniza.sk

3 Department of Cybernetics and Biomedical Engineering, VSB-Technical University of Ostrava, 70800 Ostrava, Czech Republic; michal.prauzek@vsb.cz (M.P.); jaromir.konecny@vsb.cz (J.K.)

* Correspondence: darius.andriukaitis@ktu.lt; Tel.: +370-37-300-519

\section{check for}

updates

Citation: Uskovas, G.;

Valinevicius, A.; Zilys, M.;

Navikas, D.; Frivaldsky, M.;

Prauzek, M.; Konecny, J.;

Andriukaitis, D. Driver

Cardiovascular Disease Detection

Using Seismocardiogram. Electronics 2022, 11, 484. https://doi.org/

10.3390/electronics 11030484

Academic Editor: Jose Eugenio

Naranjo

Received: 15 January 2022

Accepted: 4 February 2022

Published: 7 February 2022

Publisher's Note: MDPI stays neutral with regard to jurisdictional claims in published maps and institutional affiliations.

Copyright: (c) 2022 by the authors. Licensee MDPI, Basel, Switzerland. This article is an open access article distributed under the terms and conditions of the Creative Commons Attribution (CC BY) license (https:// creativecommons.org/licenses/by/ $4.0 /)$.
Abstract: This article deals with the treatment and application of cardiac biosignals, an excited accelerometer, and a gyroscope in the prevention of accidents on the road. Previously conducted studies say that the seismocardiogram is a measure of cardiac microvibration signals that allows for detecting rhythms, heart valve opening and closing disorders, and monitoring of patients' breathing. This article refers to the seismocardiogram hypothesis that the measurements of a seismocardiogram could be used to identify drivers' heart problems before they reach a critical condition and safely stop the vehicle by informing the relevant departments in a nonclinical manner. The proposed system works without an electrocardiogram, which helps to detect heart rhythms more easily. The estimation of the heart rate $(\mathrm{HR})$ is calculated through automatically detected aortic valve opening $(\mathrm{AO})$ peaks. The system is composed of two micro-electromechanical systems (MEMSs) to evaluate physiological parameters and eliminate the effects of external interference on the entire system. The few digital filtering methods are discussed and benchmarked to increase seismocardiogram efficiency. As a result, the fourth adaptive filter obtains the estimated $\mathrm{HR}=65$ beats per $\min (\mathrm{bmp})$ in a still noisy signal (SNR $=-11.32 \mathrm{~dB}$ ). In contrast with the low processing benefit $(3.39 \mathrm{~dB}), 27 \mathrm{AO}$ peaks were detected with a 917.56-ms peak interval mean over $1.11 \mathrm{~s}$, and the calculated root mean square error (RMSE) was $0.1942 \mathrm{~m} / \mathrm{s}^{2}$ when the adaptive filter order is 50 and the adaptation step is equal to 0.933 .

Keywords: arrhythmia; driving restrictions; adaptive digital filter; noninvasive method; heart rate

\section{Introduction}

Quality of life can be expressed by many factors, some of which are health and the opportunity to participate in favorite activities. Carrying out one's favorite work may be restricted or completely suspended due to health impairments [1]. For staff of various professions, one of the main monitoring objects is related to cardiovascular diseases, resulting in mortalities in Europe of about 4 million [2] and up to $46 \%$ of all deaths in the United States [3]. Cardiovascular diseases are a leading cause of death in the world [4], and 523.3 million people had cardiovascular disease (CVD) in $2019[5,6]$. The future prognoses of researchers are plaintive because the COVID-19 pandemic and fast aging will allegedly make the CVD numbers worse in the coming years $[5,6]$.

Cardiovascular disease is hard to predict and can render people unfit to perform some daily or professional activities or cause them to suddenly lose control for short time periods and harm others [1,7]. This transient loss of consciousness event is called syncope and can result from cardiac conditions, mostly consisting of arrhythmic events, bradyarrhythmia, or tachyarrhythmias $[8,9]$. For this reason, the American Heart Association and Heart 
Rhythm Society developed recommendations to prevent a person from putting others at risk of harm and at the same time have the opportunity to work according to a society and its culture $[1,7,10,11]$.

Athletes, pilots, drivers, and physicians are among the most prominent professions whose health statuses are regulated by strict legal provisions or directives. Arrhythmia is identified as one of the main problems of heart activity whose duration cannot exceed the prescribed time limits for electrocardiogram (ECG) short and long QT syndromes (SQTS and LQTS, respectively), namely SQRT $\leq 320 \mathrm{~ms}$ and LQTS $\geq 470 \mathrm{~ms}$ for males and LQTS $\geq 480 \mathrm{~ms}$ for females [12-14]. Athletes check their arrhythmic levels before competition and in training during exercise, beyond which they cannot be allowed to participate in competitions [12,15]. The international aviation agency has regulations stating that pilots must check that their arrhythmic levels do not reach certain limits which result in sinus bradycardia $(<40$ beats per min (bmp)), sinus tachycardia $(>100 \mathrm{bpm}$ at rest), or sino-atrial block ( $>3 \mathrm{~s}$ during the day or $>4 \mathrm{~s}$ at night). Otherwise, they must reschedule flights and contact their doctors. According to the New Standards for Driving and Cardiovascular Diseases [16] and European Commission Directive 2016/1106 [17], the threshold QT interval is LQTS > $500 \mathrm{~ms}$. The European Society of Cardiology (ESC) and the Canadian Cardiovascular Society (CCS) suggest driving restrictions in case of recurrent or unexplained syncope or substantial cardiovascular comorbidities, unless a definitive treatment can be ensured and controlled [18]. Moreover, the Japanese Circulation Society (JCS) describes driving restrictions for private and commercial patients with reflex syncope, which recommend restricting private driving until their symptoms are controlled and for commercial driving unless an effective treatment has been established [19]. The restrictions of activity unite these three risky professions and point out the importance of using a wide range of preventive actions before a sudden event happens. Furthermore, the population over the age of 65 continues to increase globally [20], which implies an increasing average age of active people with a higher risk of cardiovascular disease [14,21] in workplaces, driving vehicles, or traveling by plane. The acceptable risk of harm $(\mathrm{RH})$ estimated by the CCS created a risk estimation formula [22]. Because aging continues, the solutions require finding and using additional diagnostic facilities that prevent sudden cardio events and protect the public from injury [23].

This article deals with the proposal to introduce a preventive diagnosis of heart disease in drivers to avoid critical health conditions that accompany road incidents. Studies of long-distance drivers' working conditions show that a driver's health is exposed to various stressors, both physical and psychological [24,25]. As a result, many working hours are lost, and there is the threat of an accident on the road due to long working hours, weak metabolism, social isolation, low control, and work shifts $[14,26]$. It enforces the investigations of Canadian, German, Finnish, Swiss, Japanese [14,19], Spanish [27], and Czech Republic roads [28]. Car manufacturers have a wide range of improvements that improve drivers' working conditions and facilitate vehicle management, ergonomic solutions, and the integration of various automatic control, navigation, and alert systems [9,29,30]. Most of these automotive electronic systems are related to car control and diagnostics, but a very small part of the driver and machine interfaces is oriented toward real-time driver health diagnostics, except in sports cars [31-35]. For example, [28] points out the increase in living standards and suggests using various driver response systems which can measure unobtrusively various life functions and health conditions of drivers in order to monitor their alertness.

The most popular measurement of cardiac work is the recording of an electrocardiogram, which has advanced signal processing methods [36,37], but the daily activities of patients are constrained during measurement. Alternatively, the progress of technology allows the detecting of weak cardio signals with a better diagnostic capacity without the requirement of attaching any sensor directly to the patient's skin by using a microelectromechanical system (MEMS) [38,39]. In that case, the recording of a seismocardiogram (SCG) is possible by non-invasive measurement of low-frequency vibrations 
from 0 to $50 \mathrm{~Hz}$ of cardio cycle mechanics along the timings of corresponding cardiac events [40]. This article analyzes using the seismocardiogram method for warning a driver about possible cardiovascular disease during driving. Additionally, this article is one of the non-multiple types of research dealing with a moving patient [41] without simultaneously measuring the ECG.

The novelty of this article reflects a not yet examined location of the SCG sensor when the MEMS is integrated into the driver's safety belt for measuring the cardio mechanical vibrations. Hence, the SCG signal is affected not only by the already known respiratory and body movement artifacts but also by the movement of the car [28] and the acoustic components [42]. The aim is to obtain a useful SCG signal sufficient for heart rate calculation. Therefore, this signifies that it is necessary to select an appropriate adaptive filter algorithm and optimal settings to rapidly find an $\mathrm{AO}$ peak during driving. Consequently, the benchmark of the fourth adaptive digital filters has been examined with different settings.

The rest of the article is organized as follows. Section 2 discusses the related works and use methods, describes the system, and introduces SCG signal processing with adaptive filters. Section 3 presents the experimental data and analysis. Section 4 concludes the work of this paper and briefly introduces future works.

\section{Materials and Methods}

\subsection{Related Works}

Numerous researchers working on various driver response systems encounter autonomous car system requirements and advance them for safer driving. Technological progress over the past few generations let researchers set up unattached and attached sensor systems inside vehicles [28]. Researchers use galvanic, capacitive, mechanical, optical, or electromagnetic types of contact in different locations for monitoring the vital signs of a driver [43]. Based on this, a few monitoring methods and systems like video motion, a capacitive electrocardiogram, electroencephalogram, balistocardiogram, seismocardiogram, thermography, photoplethysmography, magnetic induction, and radar-based methods are possible $[28,43]$.

An increase in the speed of signal processing allows one to return to the mechanocardiography previously proposed and analyzed by scientists, also known as a balistocardiogram, seismocardiogram, or gyrocardiogram. Unlike the most popular clinical cardiac monitoring methods such as electrocardiogram, ultrasound cardiogram, phonocardiogram, or photoplethysmography, the measurement of mechanocardiogram is oriented toward the recording and analysis of mechanical heart transmitters.

The micromechanical system (sensor), which is micro in five types-metal, semiconductor, ceramics, polymer, and composite-is used for the measurement of these twins. In this case, the greatest attention shall be paid to the characteristics of the accelerometers and their type, of which there are five: piezo resistance, receptacle, tunnel, optical, and piezoelectric [44].

A mechanocardiogram, a balistocardiogram, seismocardiogram, or gyrocardiogram may be recorded at the same time as several parameters of a heart condition, as the transmitter of the heart muscle consists of the atrial, lung, mitral, and triple valves' opening and bruising, the movement of a heart muscle caused by a sinus node, and the propagation of the heart sound. The surveyor may provide a lot of information, thus increasing the sensitivity and resilience of an MEMS to interference, reduced dimensions $(0.08 \mathrm{~g}$, $5 \mathrm{~mm} \times 5 \mathrm{~mm} \times 1.6 \mathrm{~mm}$ [32] and $3 \mathrm{~mm} \times 3 \mathrm{~mm} \times 1 \mathrm{~mm}$ [45]), and lowering energy costs, enabling measurements with various types of smartphones (e.g., portable phones and clocks) or specialized devices. Specialized devices have been developed according to the future anchorage site, such as a chest, a chair, or a bed [46]. The ability to see heart valve tremors in MEMS sensors has led scientists to investigate the possibility of diagnosing early-stage myocardial infarction, heart failure, atrial fibrillation, and other diseases related to cardiac valves. 
Previously, the greatest attention was focused on the measurement of the balloon cardiogram when the waves of the surfaces were generated by the rise of blood pressure slopes and during the fall. Attempts have been made to monitor the work of a driver's heart by creating a special occupant evaluating the vibration of the breath at $0.13-0.73 \mathrm{~Hz}$ [47] and the vibration of the body due to ballistic forces [45]. Following a further examination of the seismocardiogram, the recording of mechanical fluctuations was caused by the movement of the heart and circulation through the main channels of the upper body. The mathematical model described clearly reflects the mechanical nature of the seismocardiogram signal and the calculation method that evaluates the forces operating in the vascular walls [48]. The balistocardiogram and seismocardiogram signals are not identifiable due to their mechanical twisting nature, although they can be measured with the same accelerometers. In both cases, it is necessary to properly select the location of the suitable sensor, such as the seat suitable for the balloon cardio signal and the limbs when the most suitable place to measure the seismocardiogram signal is to the left of the crude side rather than the chest. The measurement of the seismocardiogram signal shall include all three axes of the acceleration direction to obtain the desired accuracy [49].

The experimental studies described in relevant scientific articles show that the most extensive mechanocardiogram signals are recorded and analysed together with an electrocardiogram to better detect the beginning of systolic time intervals and to combine the observed deviations of the electrocardiogram and the seismocardiogram [50,51]. Such systems are not flexible and are not convenient for home use or during activity because the electrodes attached to the body must be used, which causes discomfort for patients. Therefore, this variant of cardiac disorders is more suitable for clinical use when there is a limited number of patients involved or sitting. One of the greatest advantages of such complementary systems is that it is possible to evaluate the dependency of the heart on the body. Lying on the left side is the riskiest heart disease, as the heart muscle is the most unloaded due to the mechanical pressure of the warrior in the heart [52,53].

Investigators have increasingly tried to perform non-invasive seismocardiogram or gyrocardiogram measurements with a smart phone without measuring the electrocardiogram. To be properly diagnosed, it is necessary to know the result of the systolic time intervals (from $149 \mathrm{~ms}$ to $1091 \mathrm{~ms}$ when the heartbeat drops from 220 to $30 \mathrm{bpm}$ [54]) and to further analyze the signal obtained by comparing the theoretical classification requirements with the practical ones. One of the first articles on automatic identification of seismocardiogram signals appeared in 2016, with an emphasis on the statistical calculation of systolic time intervals [55]. In accordance with the method proposed in this article in 2017, Finnish scientists have applied the automatic recognition of seizures to the experimental test for atrial fibrillation [45].

The seismocardiogram signal is classified as a nonstationary signal that can lead to sudden abnormalities that indicate possible signs of disease. The analysis and processing of such biosignals is problematic, requiring a range of statistical methods, including fast Fourier transformation, wavelength theory, machine learning, decision tree, and analysis of the related and unrelated attributes $[56,57]$. In summary, scientists seek to automatically detect the attribute in the biosignal so that large and small data do not accumulate. The choice of methods used for analysis depends heavily on the characteristics of the signal that characterize the frequency, time intervals, number of attributes, operation principle, and purpose of interpretation. The purpose of the interpretation is to understand the real-time alerts, diagnostics, prophylactic monitoring, and planning [56]. The analysis performed is faster and more reliable in advance of a prior signal classification based on the frequency of intervals, frequency, form of attributes, and the distribution of the signal in the separate segments $[58,59]$.

As we see in the literature analysis, measurement of the mechanocardiogram signals is not a new topic and has garnered interest from investigators since recording of the reactionary forces of Gordon's invented organism in 1877, known as a balistocardiogram, but the tests have been reduced due to the simplicity of the application of electrocardio- 
grams and the more accurate diagnosis of cardiac diseases [60]. Thanks to technological progress, micromechanical systems have become smaller and more accurate, so researchers are again encouraged to deal with the development of mechanocardiogram signals and the extension of applications, such as the use of seismocardiogram signals for the nonclinical prevention of cardiac diseases, allowing the first signs of heart problems to be observed [61] It is a very real topic to solve health problems during human daily activity and not in hospitals by using wearable technologies with the ability to alert users to the presence of health diseases. Moreover, this investigation is a small step in big research which requires creativity, know-how, and a wide range of knowledge from different study fields.

\subsection{The System Discription}

The idea of the system described in this article is based on a provision that the measurement of a driver's heart rate is carried out in a non-invasive manner without causing a sense of discomfort, avoiding ethical and private data protection aspects. Additionally, the electronic system must evaluate and predict signal changes in the noisy environment with many uncertainties, such as vibrations and body movements. The main requirement of this system is to prevent the driver from carrying out his direct function to manage the car safely.

The designed system was for the seismocardiogram measurement via an accelerometer, which was integrated in safety belt of the driver. There is a different measuring principle for measuring mechanical displacement of the chest load to that previously described in $[3,7]$, where an accelerometer was integrated in the driver seat for measuring vibration of the back of the chest. The MEMS sensor had very good contact with the body, which was closer to the heart and provided a bigger signal amplitude of the forward chest vibration. The driver could not see the integrated MEMS sensor in the safety belt, and he or she did not have to enter any personal data in order to be in line with the requirements.

A more detailed comparison of the vital sign monitoring methods is summarized in Table 1, and the present research method is included too. The advantages and disadvantages are discussed in Table 1 based on the work in $[28,43]$.

In order to reduce the system's interference and ensure the reliability of the diagnostics, the use of two accelerometers is described. Figure 1 shows the idea for where the accelerometers would be located.

The hardware of this system consists of two MPU9250 accelerometers, an ESP32 WROOM microcontroller, and an SD card reader.

The main accelerometer is integrated in the safety belt and is located at the chest during driving. The location of the second accelerometer is the seat of the driver. This location was chosen with respect to the need to measure the movement of the car and the movement of the driver's body. A second accelerometer was attached to the driver's seat because the chair is directly related to the driver and the weak vibrations of the car and the potholes on the road, which are measured for the acceleration amplitudes.

When measuring the seismocardiogram with an accelerometer, it is important to calculate the resultant of all accelerations of the accelerometer coordinates, because in this case, the most accurate reading of the seismocardiogram was obtained, with the evaluation being as a close to human accelerometer as possible [62]. This way, it was not necessary to accurately record the position of the accelerometer and perform precise corrections of the position in each case. Then, the driver wanted to change the angle of the seat back while driving. Therefore, the drive felt free and could concentrate attention only on the road. Moreover, the system did not require any additional adjustments before or after driving. 
Table 1. Advantages and disadvantages of vital sign monitoring systems used in vehicles.

\begin{tabular}{|c|c|c|c|}
\hline $\begin{array}{l}\text { Vital Sign Monitoring } \\
\text { Method }\end{array}$ & Sensor Location & Advantages & Disadvantages \\
\hline Seismocardiogram & $\begin{array}{c}\text { Safety belt } \\
\text { (this research) }\end{array}$ & $\begin{array}{c}\text { Allows measuring cardiac and respiratory } \\
\text { activity unobtrusively. } \\
\text { The signal of the three-axis accelerometer } \\
\text { characterizes specific events of } \\
\text { the heart's activity. } \\
\text { The SCG signal is measured from the } \\
\text { front of the chest. } \\
\text { The additional reference signal is not required. } \\
\text { The safety belt obliges using the vital sign } \\
\text { monitoring system automatically. }\end{array}$ & Requires solving noise issues. \\
\hline Seismocardiogram & Worn sensor & $\begin{array}{c}\text { Allows measuring cardiac and respiratory } \\
\text { activity unobtrusively. } \\
\text { The signal of the three-axis accelerometer } \\
\text { characterizes specific events of } \\
\text { the heart's activity. } \\
\text { Does not require a reference signal. }\end{array}$ & $\begin{array}{l}\text { Driver required to wear } \\
\text { sensor on the body. } \\
\text { Requires solving noise issues. }\end{array}$ \\
\hline Seismocardiogram & Back of the car seat & $\begin{array}{l}\text { Allows measuring cardiac and respiratory } \\
\text { activity unobtrusively. } \\
\text { The signal of the three-axis accelerometer } \\
\text { characterizes specific events of } \\
\text { the heart's activity }[28,43] .\end{array}$ & $\begin{array}{l}\text { The seat attenuates the SCG signal. } \\
\text { Requires a reference signal, which } \\
\text { increases signal processing duration. }\end{array}$ \\
\hline Balistocardiogram & Car seat & $\begin{array}{l}\text { Allows measuring cardiac and respiratory } \\
\text { activity unobtrusively. } \\
\text { Records the cardio, mechanic, and lung } \\
\text { vibrations and the momentum of the blood } \\
\text { pulse traveling down to the aorta [28]. }\end{array}$ & $\begin{array}{c}\text { The noise of car motor vibrations may } \\
\text { make measurement difficult [28]. } \\
\text { Requires a reference signal. }\end{array}$ \\
\hline $\begin{array}{l}\text { Capacitive } \\
\text { electrocardiogram }\end{array}$ & $\begin{array}{l}\text { Steering wheel } \\
\text { Car seat } \\
\text { Back of car seat }\end{array}$ & $\begin{array}{l}\text { Records electrical activity of the heart muscle. } \\
\text { Still the most valuable physiological signal. } \\
\text { No galvanic contact with the body. } \\
\text { Electrically insulated and remains stable in } \\
\text { long-term applications [43]. }\end{array}$ & $\begin{array}{l}\text { Both hands have to touch two } \\
\text { different parts of the wheel. } \\
\text { Requires an infinitely high } \\
\text { ohmic resistance [43]. }\end{array}$ \\
\hline Video monitoring & Camera-based & $\begin{array}{c}\text { Allows measuring cardiac } \\
\text { activity unobtrusively. } \\
\text { No contact required to monitor a } \\
\text { driver or passengers. } \\
\text { Monitoring of respiratory and temperature can } \\
\text { happen in complete darkness. } \\
\text { Driver drowsiness and attention detection. } \\
\text { Driver stress and pain detection by analyzing } \\
\text { facial expressions }[28,43] \text {. }\end{array}$ & $\begin{array}{l}\text { Requires free line of sight. } \\
\text { Absence of privacy. } \\
\text { Sufficient light cannot be guaranteed } \\
\text { for operating in the far } \\
\text { infrared spectrum. } \\
\text { Shadows from other cars and trees can } \\
\text { rapidly change the signal }[28,43] .\end{array}$ \\
\hline $\begin{array}{l}\text { Radar system } \\
\text { transmitter- } \\
\text { receiver system } \\
\text { Doppler radar }\end{array}$ & $\begin{array}{l}\text { Front radar } \\
\text { Back of car seat }\end{array}$ & $\begin{array}{l}\text { Allows measuring cardiac and respiratory } \\
\text { activity unobtrusively. } \\
\text { No contact required. } \\
\text { Uses high-frequency electromagnetic waves } \\
\text { that are emitted and reflected by } \\
\text { the chest's surface }[28,43] \text {. }\end{array}$ & $\begin{array}{l}\text { The heart-related motions are very } \\
\text { small and hard to detect [43]. }\end{array}$ \\
\hline Electroencephalogram & Special helmet & $\begin{array}{l}\text { Allows measuring concentration, reaction } \\
\text { time, and cognitive state, as well as } \\
\text { drowsiness of drivers [43]. }\end{array}$ & The measurement system is complex. \\
\hline
\end{tabular}




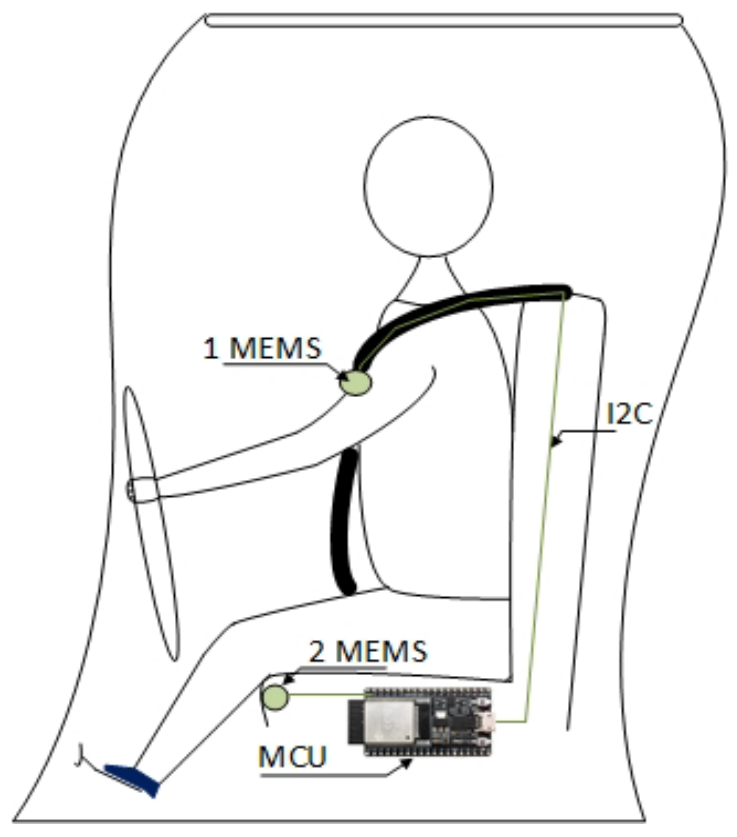

(a)

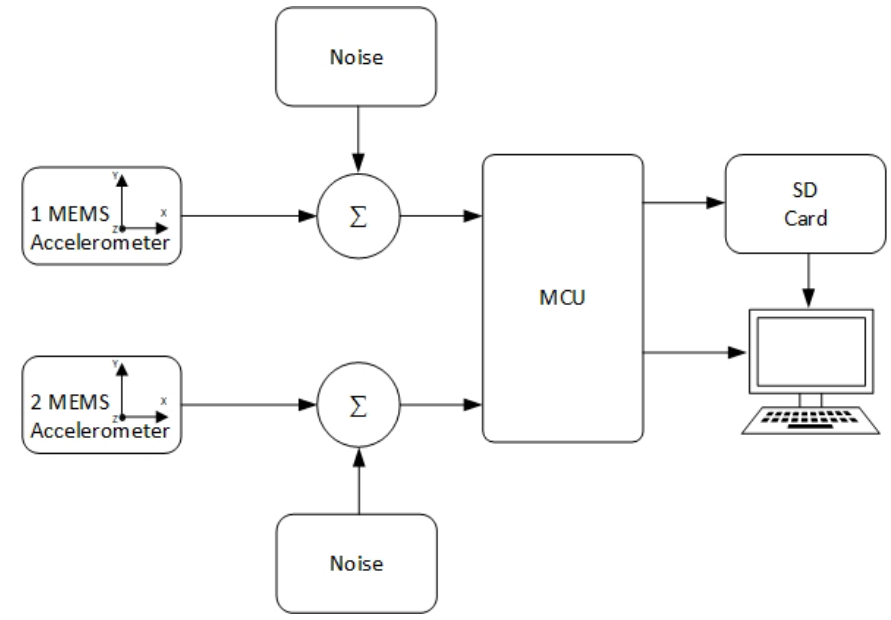

(b)

Figure 1. Driver seismocardiogram measurement system with two accelerometers. (a) Driver seismocardiogram measurement system inside car. (b) Structure of measurement data collection and processing system.

$$
s(t)=\sqrt{s_{x}(t)^{2}+s_{y}(t)^{2}+s_{z}(t)^{2}}
$$

The total acceleration (Equation (1)) required was calculated on the basis Figure 2 that a better SCG signal could be obtained instead of only the z-axis, as in other previous studies [54,63]. In addition to preparing this signal for processing, normalization of the total acceleration was performed. As a result, the power of the big vibrations reduced and impacted the input signal processing.

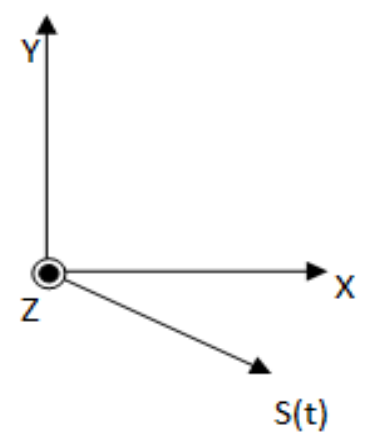

Figure 2. Resultant of three accelerometer coordinates.

This did not disturb the driver during the trip, and this system avoided personal identity regulations. The data were collected on an SD card if needed.

\subsection{The Signal Processing}

Adaptive filtering has many advantages and is useful for biomedical applications. Unlike other filters, an adaptive filter can self-adjust the filter coefficients to a rapidly and unpredictably changed signal. The principle of operation of the adaptive filter is defined by Equation (2) $[64,65]$ :

$$
e(n)=d(n)-y(n)
$$


The operation of this filter is based on the tendency of the filter output signal $y(n)$ to correspond as closely as possible to the affected signal $d(n)$ through the feedback response of the error signal $e(n)$ to the coefficients $\mathrm{H}(\mathrm{z})$ of the filter transfer function so that $e(n)$ is zero $[64,65]$ :

$$
y(n)=\sum_{k=1}^{L} \mathrm{~b}_{n}(n) x(n-k)
$$

The structure shows in Figure 3 that, based on the fact that the SCG signal is measured in the frequency band of $1-20 \mathrm{~Hz}$, it feeds the signal of the frequency band of interest to the adaptive filter to make the adaptive filter much more efficient and effective $[66,67]$. For this, a finite impulse response filter (FIR) or an infinite impulse response filter (IIR) can be used. As a result, one accelerometer can be used for measurement. Apart from the fundamental adaptive filter configuration, the frequency band is $5-45 \mathrm{~Hz}$ for the adaptive filter with a delay (Figure 4). Additionally, the performance for detecting AO peaks was analyzed with the FIR and IRR filters:

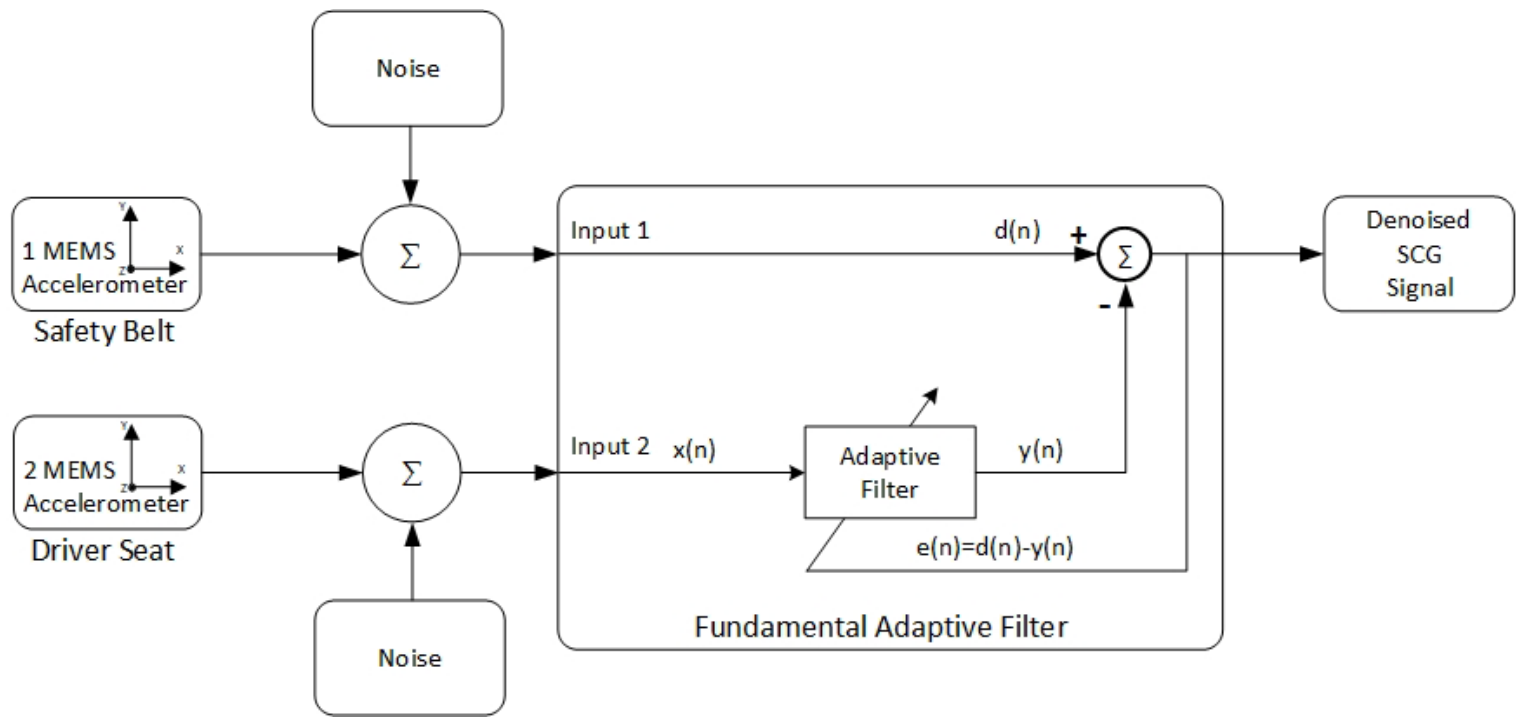

Figure 3. Fundamental adaptive filter configuration.

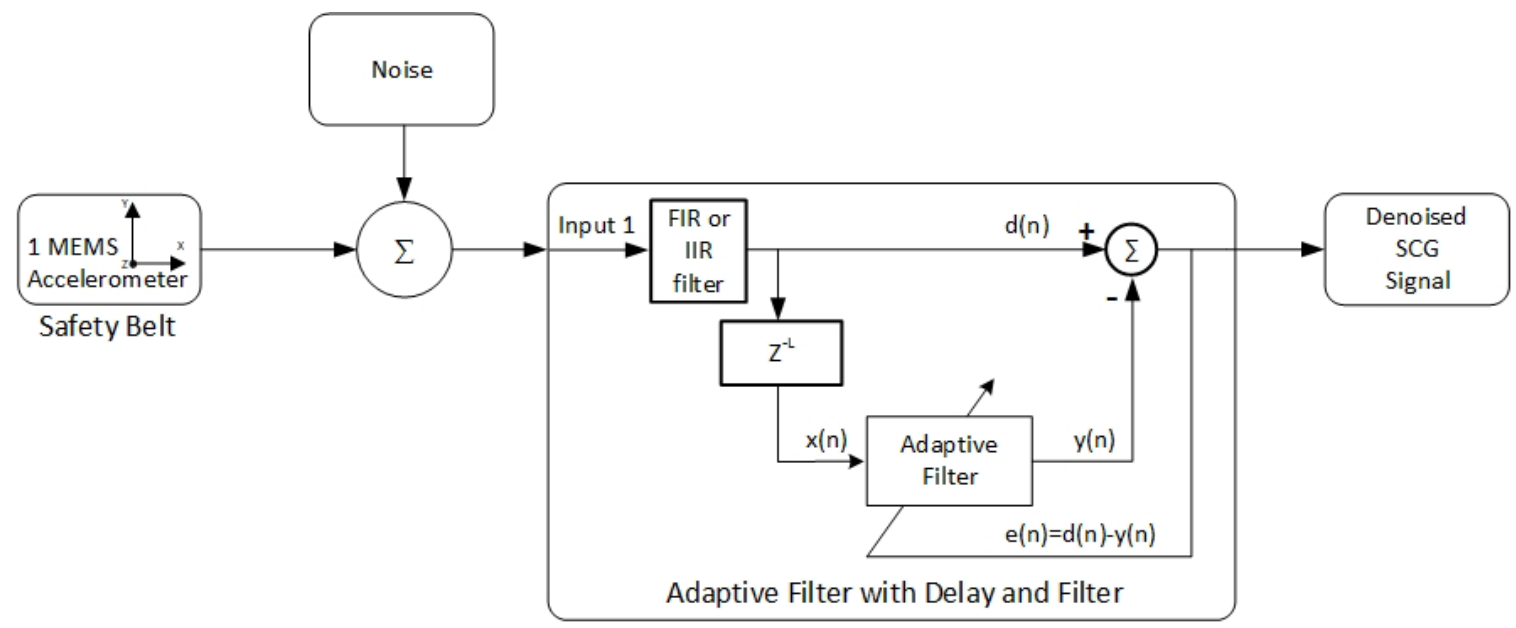

Figure 4. Adaptive filter configuration.

The adaptive filter modifies the filter coefficients $\mathrm{b}_{n}(k)$ according signal property and they can be calculated with Equation (4) [64]. The estimation accuracy of coefficients $b_{n}(k)$ 
depends to rule how changes the convergence parameter $\Delta$, which lie in the range described in Equation (5) [64].

$$
\begin{gathered}
\mathrm{b}_{n}(k)=\mathrm{b}_{n-1}(k)+\Delta e(n) x(n-k) \\
0<\Delta<\frac{1}{10 L P_{x}}
\end{gathered}
$$

where: $L$ is length of the FIR filter and $P_{x}$ power of the signal in the input.

The power is calculated using Equation (6) [64]:

$$
P_{x} \approx \frac{1}{N-1} \sum_{n=1}^{N} x^{2}(n)
$$

\section{Results and Discussion}

The proposed system collects data without additional measurements, except for seismocardiogram detection. The main aim of this system is to monitor the heart rate with one system and, at the same time, avoid disturbing human activity during the driving process.

The duration of the interval between two peaks has a few requirements. The first requirement sets a $410-\mathrm{ms}$ minimal time interval between two peaks. This requirement helps to avoid incorrectly detecting mistakes in the opening moments of the aorta. The second limitation relates to the signal's minimal level, which means that the peak has to be above this minimal level, which is equal to the total signal power. Each adaptive filter has its own minimal level, depending on the signal processing results.

\section{Experimental Results}

The data were collected to perform a deeper analysis of the proposed system's performance. Figure 5 shows the signal processing results, where the top diagram indicates the seismocardiogram signal in the input. The second diagram shows the adaptive filter learning processes that calculate the adaptive error. As a result, the third diagram indicates the filtered signal and looks like the driver's seismocardiogram. The fourth diagram shows that the third adaptive filter could recognize patterns of heart beats which represent the aorta opening in the seismocardiogram.

The calculated signal-to-noise ratio of the third adaptive filter $(\mathrm{SNR}=-8.0627 \mathrm{~dB})$ was negative, indicating huge noise in the environment. Thus, the fourth adaptive filter was analyzed, which first filtrated the SCG signal with the IIR filter (filter order of five) and afterward with an adaptive filter with a delay (order of 5) (Figure 4). In that case, Figure 6 presents three signal processing diagrams of the fourth adaptive filter, showing the adaptation error, signal in the fourth adaptive filter output, and efficiency of the adaptive filter.

Figure 6 shows that the denoised signal $y(t)$ in the output of the fourth adaptive filter was clearer and could mark places with similar form (black ellipse), which repeated but had different amplitudes. As a result, this partly conformed to publications of other authors and enforced the importance of continuing research by creating and developing new methods.

Figure 7 shows how the variation of the signal-to-nose ratios of the adaptive filters depended on the filter order. An interesting fact is that the signal-to-noise ratio was negative. This means that the adaptive filter did not perform as well as the filtration. Therefore, the filtrated signal had noise. This situation is not typical compared with other signals, such as with electrocardiogram measurement. 


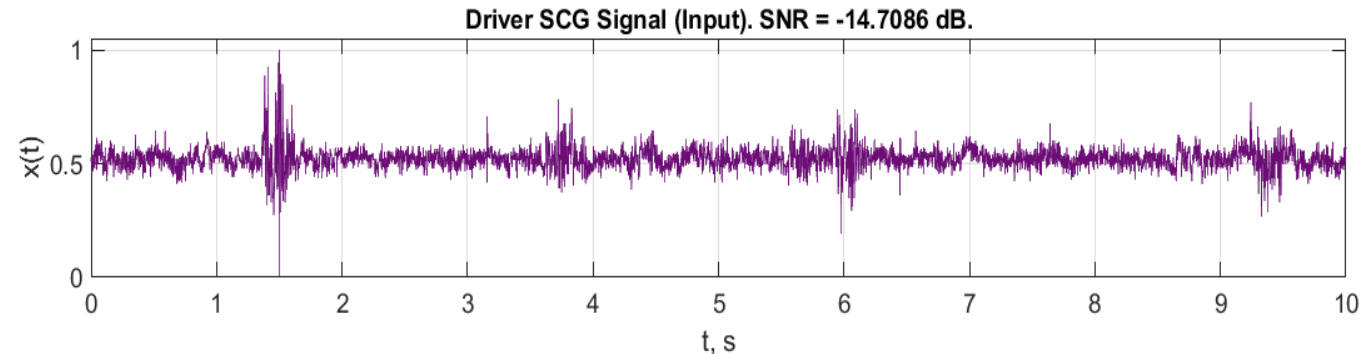

(a)

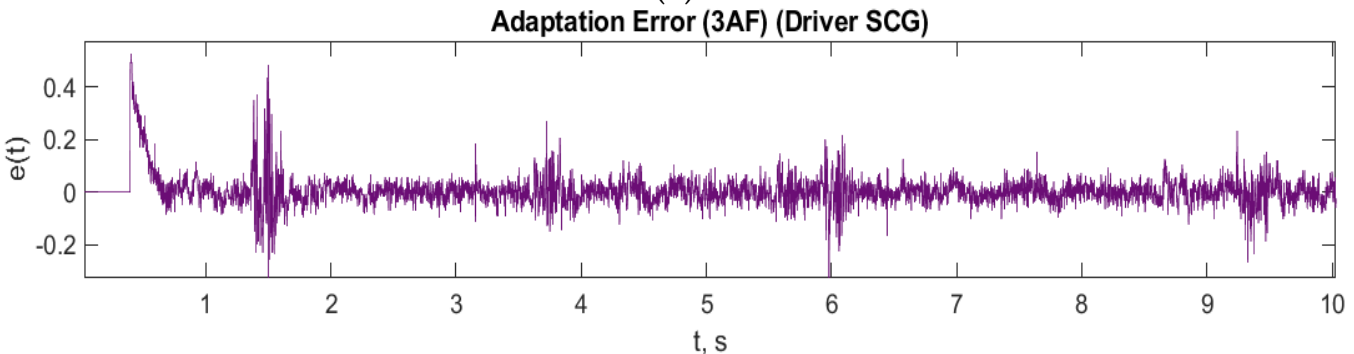

(b)

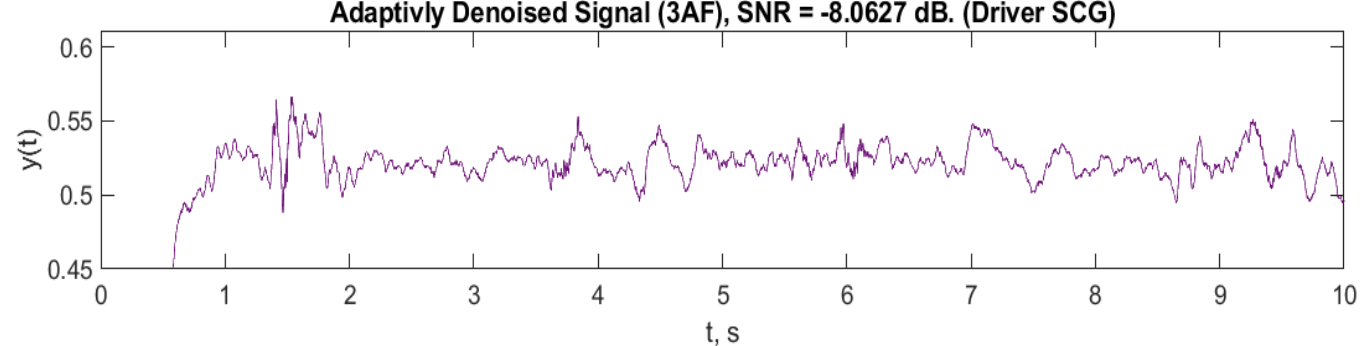

(c)

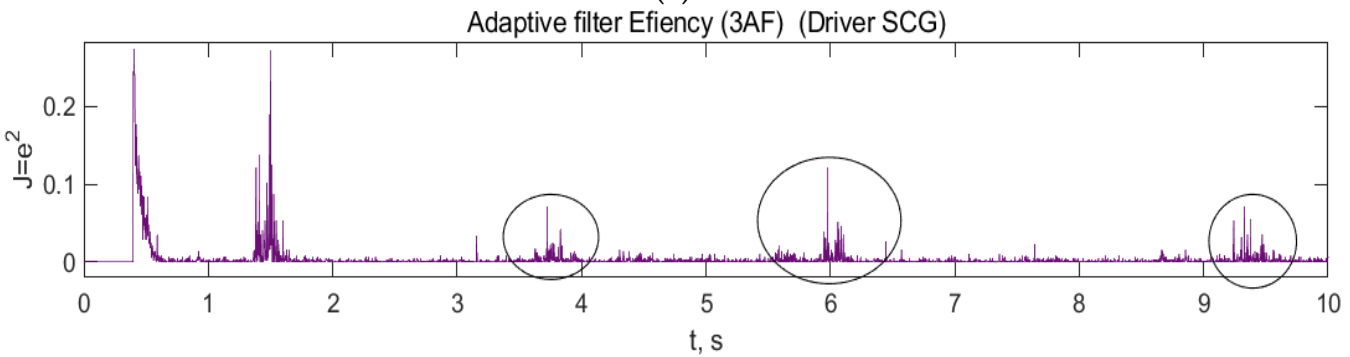

(d)

Figure 5. Processing of the driver's seismocardiogram signal in the third adaptive filter with sample delay order of 5 and the FIR filter in the input. (a) SCG signal on input. (b) Adaptation error of the third adaptive filter. (c) Adaptively filtrated signal. (d) The efficiency of the adaptative filter.

On the other hand, the received signal managed to find the peak markings and heart rate calculations, while the signal had a negative value for the SNR in all adaptive filters from the first one to the fourth $-7.61 \mathrm{~dB},-7.22 \mathrm{~dB},-8.06 \mathrm{~dB}$, and $-11.32 \mathrm{~dB}$, respectively. The processing benefit of the fourth filter was the smallest ( $3.39 \mathrm{~dB})$, and the others were about $7 \mathrm{~dB}$.

Figure 8 shows the driver's seismocardiogram with detected peaks and a calculated heart rate of 65 beats per minute. 


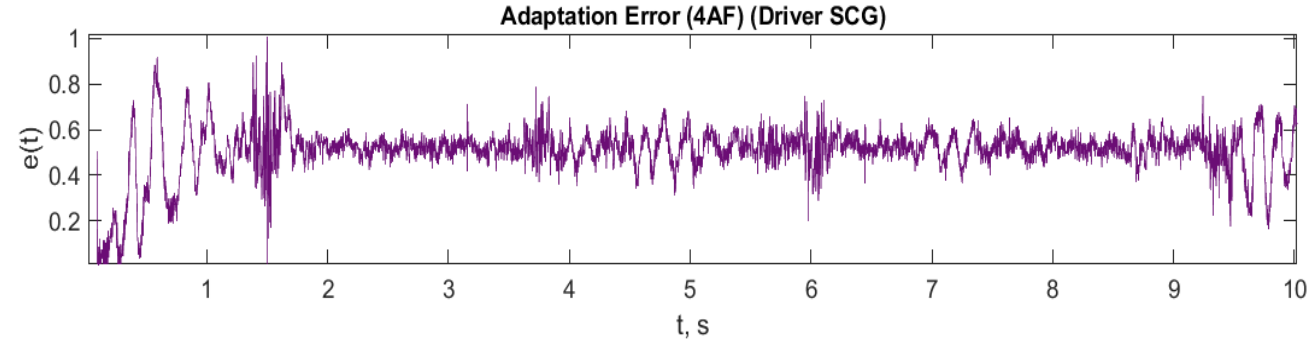

(a)

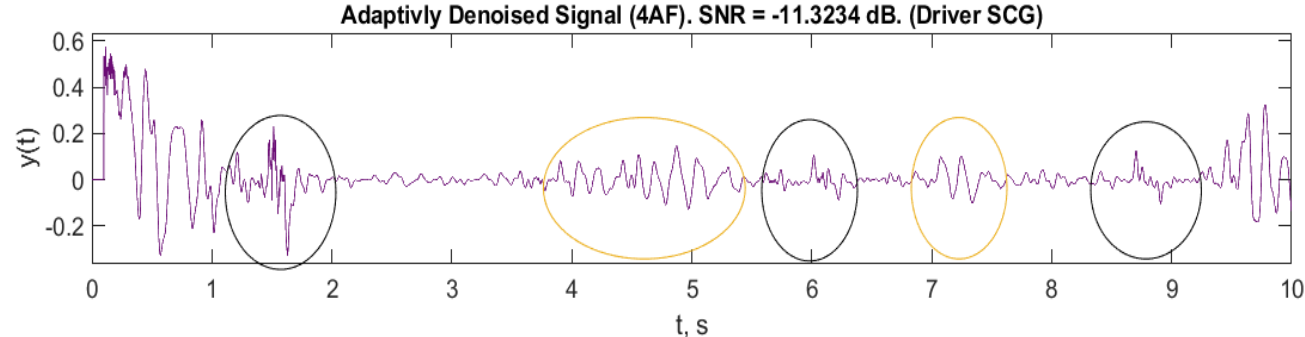

(b)

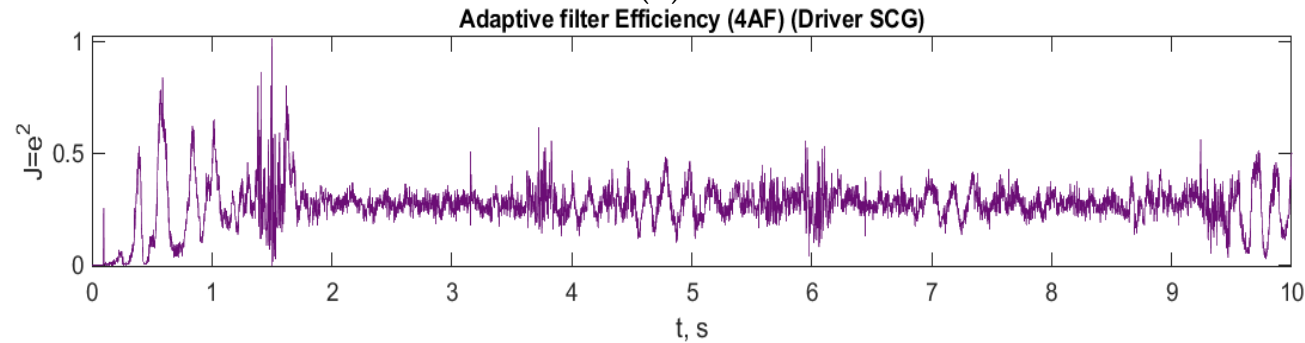

(c)

Figure 6. The fourth adaptive filter. (a) Adaptation error of the fourth adaptive filter. (b) The fourth adaptively filtrated signal. (c) Adaptation efficiency.

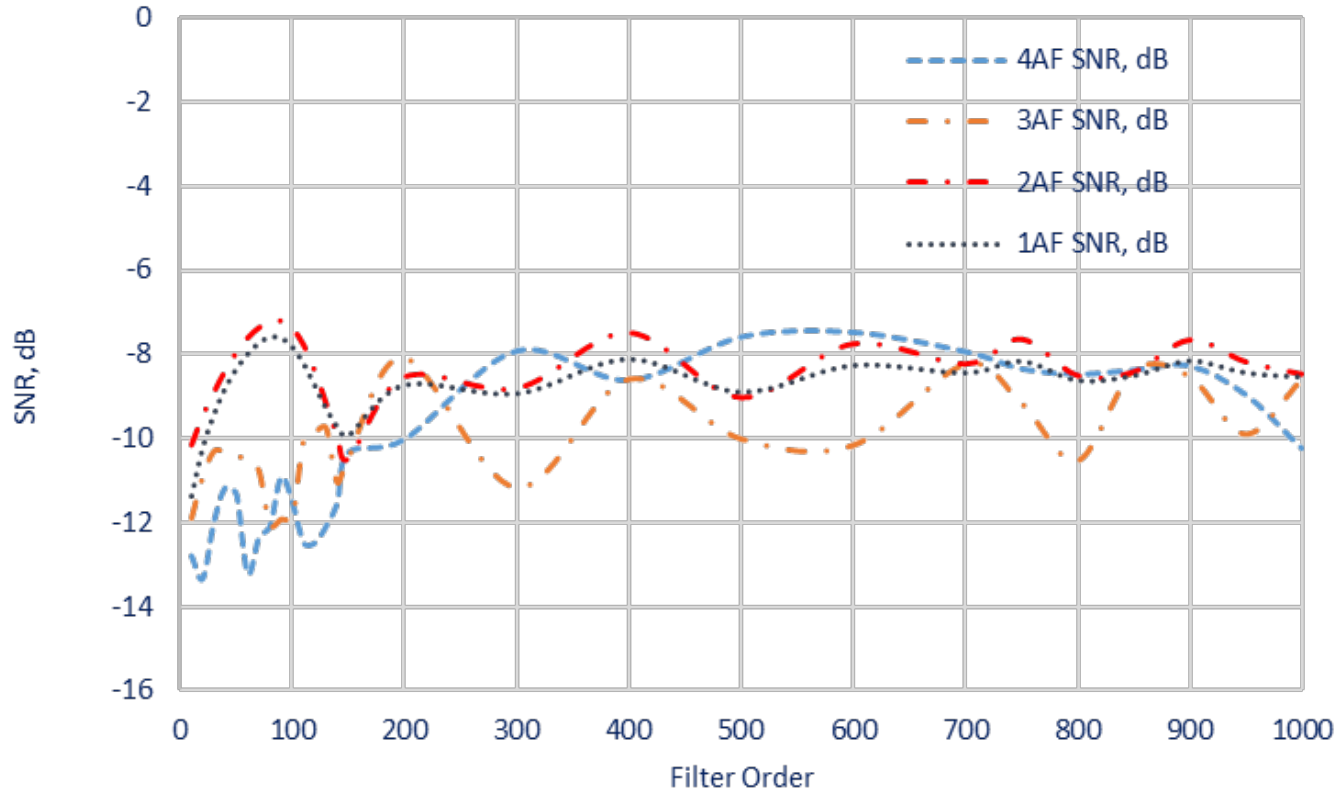

Figure 7. Signal-to-noise rate's dependence on the adaptive filter order. 


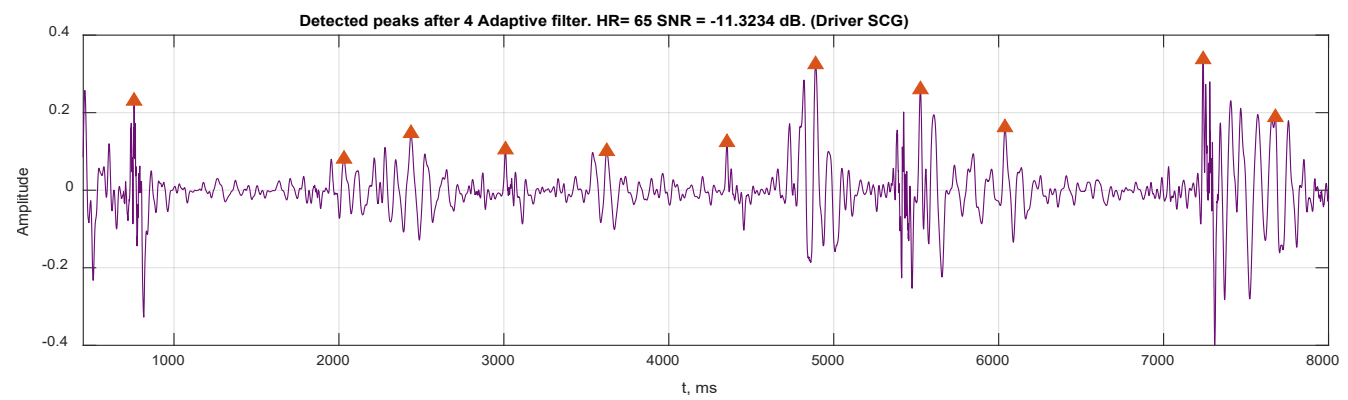

Figure 8. Driver seismocardiogram after the fourth adaptive filter and detected peaks.

Additionally, calculations have been performed to better understand the seismocardiogram signal and the behaviour of four different adaptive filter configurations. The settings of the adaptive filters and signal processing data are tabulated in Table 2.

Table 2. Adaptive filter processing data.

\begin{tabular}{ccccc}
\hline & Adaptive Filter 1 & Adaptive Filter 2 & Adaptive Filter 3 & Adaptive Filter 4 \\
\hline Filter order & 90 & 90 & 200 & 50 \\
\hline mu AF step & $1.0133 \times 10^{-3}$ & $1.0133 \times 10^{-3}$ & $5.0855 \times 10^{-3}$ & $9.3302 \times 10^{-1}$ \\
\hline Heart rate (beats $/ \mathrm{min})$ & 109 & 107 & 111 & 65 \\
\hline RMS $\left(\mathrm{m} / \mathrm{s}^{2}\right)$ & 0.5212 & 0.5208 & 0.5198 & 0.0684 \\
\hline SNR (dB) & -7.61 & -7.22 & -8.06 & -11.32 \\
\hline RMSE $\left(\mathrm{m} / \mathrm{s}^{2}\right)$ & 0.0472 & 0.0370 & 0.0248 & 0.1942 \\
\hline Detected peaks number & 53 & 52 & 53 & 27 \\
\hline Peak interval mean $(\mathrm{ms})$ & 549.07 & 558.21 & 117.22 & 917.56 \\
\hline Peak Interval STD & 117.82 & 127.11 & 1.09 & 635.12 \\
\hline Processing time $(\mathrm{s})$ & 57.69 & 1.09 & 6.65 & 1.11 \\
\hline Processing benefit $(\mathrm{dB})$ & 7.10 & 7.49 & 3.39 \\
\hline
\end{tabular}

The data in the table show that increasing the minimum duration limit between pulses decreased the heart rate and coincided with the value of the standard deviation between the detected peaks, which means greater reliability for the measurement. In all cases, the root mean square error (RMSE) of the third adaptive filter was $0.0248\left(\mathrm{~m} / \mathrm{s}^{2}\right)$, and it was the smallest value compared with the other filters, indicating the stability of the signal peak level of the received signal at this adaptive filter output. The RMSE of the fourth adaptive filter $\left(0.1942\left(\mathrm{~m} / \mathrm{s}^{2}\right)\right.$ indicates smaller stability of the received signal peaks' levels. Hence, the seismocardiogram signal was not stable.

Figure 9 shows the benchmark of all the adaptive filter autocorrelations and presents that the signals after processing did not change enough from the input signal in the first three adaptive filters. Alternatively, the signal in the fourth was evidently changed from 5 to 20 time lags.

Additionally, the data show that the fourth filter detected 27 fewer peaks than the other 53 peaks. The standard deviation of 635.12 for the peak intervals shows that in these cases, the system did not find any peak.

Measurement of the processing duration was performed, which shows that the typical adaptive filter without delay spent the longest time in processing $(57.69 \mathrm{~s})$. As a result, this adaptive filter is not recommended for signal processing of seismocardiograms. 


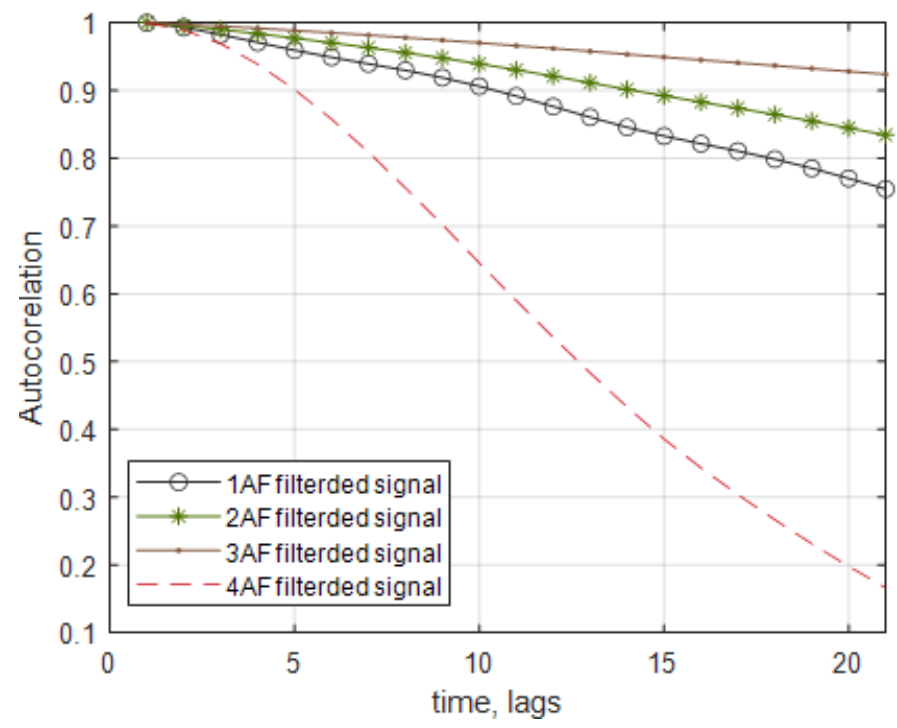

Figure 9. Autocorrelations of the filtered seismocardiogram signals.

\section{Conclusions}

A system monitoring driver cardiovascular disease has been described. Several advantages and disadvantages of the SCG were described and compared with alternative investigations. The results of the experiments show that the developed system collected sufficient data and could interpret them later using an adaptive filter. As a result, the fourth adaptive filter obtained an estimated $\mathrm{HR}=65$ beats per $\min (\mathrm{bpm})$ in a still-noisy signal $(\mathrm{SNR}=-11.32 \mathrm{~dB})$. In contrast with the low processing benefit $(3.39 \mathrm{~dB}), 27 \mathrm{AO}$ peaks were detected with a 917.56-ms peak interval mean over $1.11 \mathrm{~s}$, and the calculated root mean square error (RMSE) was $0.1942 \mathrm{~m} / \mathrm{s}^{2}$ when the adaptive filter order was 50 and the adaptation step was equal to 0.933 .

Signal processing was performed using four adaptive filter algorithms and compared. The results show that the filtered signal was noisy, and more advanced adaptive filter algorithms and a sensor system with few accelerometers are needed for better signal acquisition.

The proposed system and methodology can be useful and integrated in car safety systems. For better performance, more research and improvements to the system are needed. Furthermore, future works will relate to improving the processing methods by including machine learning with an additional mathematical model of the seismocardiogram.

Author Contributions: Conceptualization, G.U., A.V. and D.N.; methodology, D.A., M.Z. and M.P.; software, G.U. and J.K.; validation, D.A., A.V., M.Z., M.P. and M.F.; visualization, G.U., D.N. and A.V.; investigation, D.N., G.U., D.A., A.V. and M.Z.; resources, M.Z., M.F., J.K. and M.P.; data curation, D.N., M.Z. and G.U.; writing-original draft preparation, G.U., A.V., D.A. and M.P.; writing-review and editing, D.N., D.A., J.K. and M.F.; supervision, A.V.; funding acquisition, M.Z. and D.A. All authors have read and agreed to the published version of the manuscript.

Funding: This research received no external funding.

Conflicts of Interest: The authors declare no conflict of interest.

\section{References}

1. $\quad$ Epstein, A.E.; Miles, W.M.; Benditt, D.G.; Camm, A.J.; Darling, E.J.; Friedman, P.L.; Garson, A.; Harvey, J.C.; Kidwell, G.A.; Klein, G.J.; et al. Personal and public safety issues related to arrhythmias that may affect consciousness: Implications for regulation and physician recommendations. A medical/scientific statement from the American Heart Association and the North American Society of Pacing. Circulation 1996, 94, 1147-1166. [CrossRef] [PubMed]

2. Pencina, M.J.; Navar, A.M.; Wojdyla, D.; Sanchez, R.J.; Khan, I.; Elassal, J.; D’agostino, R.B.; Peterson, E.D.; Sniderman, A.D. Quantifying Importance of Major Risk Factors for Coronary Heart Disease. Circulation 2019, 139, 1603-1611. [CrossRef] [PubMed] 
3. Virani, S.S.; Alonso, A.; Benjamin, E.J.; Bittencourt, M.S.; Callaway, C.W.; Carson, A.P.; Chamberlain, A.M.; Chang, A.R.; Cheng, S.; Delling, F.N. Heart disease and stroke statistics-2020 update: A report from the American Heart Association. Circulation 2020, 141, E139-E596. [CrossRef] [PubMed]

4. Cardiovascular Diseases (CVDs). Available online: https://www.who.int/news-room/fact-sheets/detail/cardiovasculardiseases-(cvds) (accessed on 28 December 2021).

5. Virani, S.S.; Alonso, A.; Aparicio, H.J.; Benjamin, E.J.; Bittencourt, M.S.; Callaway, C.W.; Carson, A.P.; Chamberlain, A.M.; Cheng, S.; Delling, F.N. Heart Disease and Stroke Statistics-2021 Update A Report from the American Heart Association Circulation 2021, 143, E254-E743. [CrossRef]

6. Ruthmann, N. AHA: Heart Disease Remains Leading Cause of Death Worldwide; Trends Discouraging. Available online: https: / / www.healio.com/news / cardiology / 20210127/aha-heart-disease-remains-leading-cause-of-death-worldwide-trendsdiscouraging (accessed on 28 December 2021).

7. $\quad$ Epstein, A.E.; Baessler, C.A.; Curtis, A.B.; Estes, N.A.A.M.; Gersh, B.J.; Grubb, B.; Mitchell, L.B. Addendum to “Personal and Public Safety Issues Related to Arrhythmias That May Affect Consciousness: Implications for Regulation and Physician Recommendations: A Medical/Scientific Statement From the American Heart Association and the North American Society of Pacing and Electrophysiology". Circulation 2007, 115, 1170-1176.

8. Brignole, M.; Moya, A.; De Lange, F.J.; Deharo, J.C.; Elliott, P.M.; Fanciulli, A.; Fedorowski, A.; Furlan, R.; Kenny, R.A.; Martín, A.; et al. 2018 ESC Guidelines for the diagnosis and management of syncope. Eur. Heart J. 2018, 39, 1883-1948. [CrossRef]

9. Margulescu, A.D.; Anderson, M.H. A review of driving restrictions in patients at risk of syncope and cardiac arrhythmias associated with sudden incapacity: Differing global approaches to regulation and risk. Arrhythmia Electrophysiol. Rev. 2019, 8, 90-98. [CrossRef]

10. Sonmezocak, T.; Kurt, S. Detection of EMG Signals by Neural Networks Using Autoregression and Wavelet Entropy for Bruxism Diagnosis. Elektron. Elektrotechnika 2021, 27, 11-21. [CrossRef]

11. Nguyen, T.-N.; Nguyen, T.-H. Deep Learning Framework with ECG Feature-Based Kernels for Heart Disease Classification. Electron. Electr. Eng. 2021, 27, 48-59. [CrossRef]

12. Drezner, J.A.; Ackerman, M.J.; Cannon, B.C.; Corrado, D.; Heidbuchel, H.; Prutkin, J.M.; Salerno, J.C.; Anderson, J.; Ashley, E.; Asplund, C.A.; et al. Abnormal electrocardiographic findings in athletes: Recognising changes suggestive of primary electrical disease. Br. J. Sports Med. 2013, 47, 153-167. [CrossRef]

13. Guettler, N.; Bron, D.; Manen, O.; Gray, G.; Syburra, T.; Rienks, R.; D’Arcy, J.; Davenport, E.D.; Nicol, E.D. Management of cardiac conduction abnormalities and arrhythmia in aircrew. Heart 2019, 105, S38-S49. [CrossRef]

14. Klein, H.H.; Sechtem, U.; Trappe, H.-J. Fitness to Drive in Cardiovascular Disease. Dtsch. Arztebl. Int. 2017, 114, 692-701. [CrossRef]

15. Al-Khatib, S.M.; Stevenson, W.G.; Ackerman, M.J.; Bryant, W.J.; Callans, D.J.; Curtis, A.B.; Deal, B.J.; Dickfeld, T.; Field, M.E.; Fonarow, G.C.; et al. 2017 AHA/ACC/HRS Guideline for Management of Patients with Ventricular Arrhythmias and the Prevention of Sudden Cardiac Death: A Report of the American College of Cardiology/American Heart Association Task Force on Clinical Practice Guidelines and the Heart. J. Am. Coll. Cardiol. 2018, 72, e91-e220. [CrossRef]

16. Vijgen, J.; Albrecht, M.; Kumar, A.; Steen, T.; Tant, M.; Lerecouvreux, M.; Jung, W.; Rugina, M.; Falk, V.; Moerz, R.; et al. New Standards for Driving and Cardiovascular Diseases. Eur. Work. Gr. Driv. Cardiovasc. Dis. 2013, 1, 59.

17. EUR-Lex-32016L1106-EN-EUR-Lex. Available online: https:/ /eur-lex.europa.eu/eli/dir/2016/1106/oj/deu (accessed on 3 January 2022).

18. Numé, A.K.; Gislason, G.; Christiansen, C.B.; Zahir, D.; Hlatky, M.A.; Torp-Pedersen, C.; Ruwald, M.H. Syncope and motor vehicle crash risk: A Danish nationwide study. JAMA Intern. Med. 2016, 176, 503-510. [CrossRef]

19. Sumiyoshi, M. Driving restrictions for patients with reflex syncope. J. Arrhythmia 2017, 33, 590-593. [CrossRef]

20. Jaul, E.; Barron, J. Age-Related Diseases and Clinical and Public Health Implications for the 85 Years Old and Over Population. Front. Public Health 2017, 5, 335. [CrossRef]

21. Kassebaum, N.J.; Arora, M.; Barber, R.M.; Brown, J.; Carter, A.; Casey, D.C.; Charlson, F.J.; Coates, M.M.; Coggeshall, M.; Cornaby, L.; et al. Global, regional, and national disability-adjusted life-years (DALYs) for 315 diseases and injuries and healthy life expectancy (HALE), 1990-2015: A systematic analysis for the Global Burden of Disease Study 2015. Lancet 2016, 388, 1603-1658. [CrossRef]

22. Simpson, C.; Ross, D.; Dorian, P. CCS Consensus Conference 2003: Assessment of the cardiac patient for fitness to drive and fly-Executive summary. Can. J. Cardiol. 2004, 20, 1313-1323.

23. Pockevicius, V.; Markevicius, V.; Cepenas, M.; Andriukaitis, D.; Navikas, D. Blood Glucose Level Estimation Using Interdigital Electrodes. Elektron. Elektrotechnika 2013, 19, 71-74. [CrossRef]

24. Jain, P.K.; Tiwari, A.K. Heart monitoring systems-A review. Comput. Biol. Med. 2014, 54, 1-13. [CrossRef]

25. Barbic, F.; Casazza, G.; Zamunér, A.R.; Costantino, G.; Orlandi, M.; Dipaola, F.; Capitanio, C.; Achenza, S.; Sheldon, R.; Furlan, R. Driving and working with syncope. Auton. Neurosci. Basic Clin. 2014, 184, 46-52. [CrossRef]

26. Chen, C.C.; Shiu, L.J.; Li, Y.L.; Tung, K.Y.; Chan, K.Y.; Yeh, C.J.; Chen, S.C.; Wong, R.H. Shift Work and Arteriosclerosis Risk in Professional Bus Drivers. Ann. Epidemiol. 2010, 20, 60-66. [CrossRef]

27. García Lledó, A.; Valdés Rodríguez, E.; Ozcoidi Val, M. Heart Disease and Vehicle Driving: Novelties in European and Spanish Law. Rev. Española Cardiol. (Engl. Ed.) 2018, 71, 892-894. [CrossRef] 
28. Sidikova, M.; Martinek, R.; Kawala-Sterniuk, A.; Ladrova, M.; Jaros, R.; Danys, L.; Simonik, P. Vital sign monitoring in car seats based on electrocardiography, ballistocardiography and seismocardiography: A review. Sensors 2020, 20, 5699. [CrossRef]

29. Surgailis, T.; Valinevicius, A.; Markevicius, V.; Navikas, D.; Andriukaitis, D. Avoiding forward car collision using stereo vision system. Elektron. Elektrotechnika 2012, 18, 37-40. [CrossRef]

30. Soni, N.; Malekian, R.; Andriukaitis, D.; Navikas, D. Internet of Vehicles based approach for road safety applications using sensor technologies. Wirel. Pers. Commun. 2019, 105, 1257-1284. [CrossRef]

31. Ieremeiev, O.; Lukin, V.; Okarma, K.; Egiazarian, K. Full-Reference Quality Metric Based on Neural Network to Assess the Visual Quality of Remote Sensing Images. Remote Sens. 2020, 12, 2349. [CrossRef]

32. Paterova, T.; Prauzek, M. Estimating Harvestable Solar Energy from Atmospheric Pressure Using Deep Learning. Elektron. Elektrotechnika 2021, 27, 18-25. [CrossRef]

33. Sotner, R.; Domansky, O.; Jerabek, J.; Herencsar, N.; Petrzela, J.; Andriukaitis, D. Integer-and Fractional-Order Integral and Derivative Two-Port Summations: Practical Design Considerations. Appl. Sci. 2020, 10, 54. [CrossRef]

34. Prauzek, M.; Konecny, J. Optimizing of Q-Learning Day/Night Energy Strategy for Solar Harvesting Environmental Wireless Sensor Networks Nodes. Elektron. Elektrotechnika 2021, 27, 50-56. [CrossRef]

35. Skovierova, H.; Pavelek, M.; Okajcekova, T.; Palesova, J.; Strnadel, J.; Spanik, P.; Halašová, E.; Frivaldsky, M. The Biocompatibility of Wireless Power Charging System on Human Neural Cells. Appl. Sci. 2021, 11, 3611. [CrossRef]

36. Saini, S.K.; Gupta, R. Artificial intelligence methods for analysis of electrocardiogram signals for cardiac abnormalities: State-ofthe-art and future challenges. Artif. Intell. Rev. 2021, 1-47. [CrossRef]

37. Maršánová, L.; Ronzhina, M.; Smíšek, R.; Vítek, M.; Němcová, A.; Smital, L.; Nováková, M. ECG features and methods for automatic classification of ventricular premature and ischemic heartbeats: A comprehensive experimental study. Sci. Rep. 2017, 7, 1-11. [CrossRef]

38. Taymanov, R.; Sapozhnikova, K. What makes sensor devices and microsystems 'intelligent' or 'smart'? In Smart Sensors and MEMS, 2nd ed.; Elsevier: Amsterdam, The Netherlands, 2018; pp. 1-22, ISBN 9780081020562.

39. Yang, C.; Tavassolian, N. Combined Seismo- and Gyro-Cardiography. IEEE J. Biomed. Health Inform. 2018, $22,1466-1475$. [CrossRef]

40. Sahoo, P.K.; Thakkar, H.K.; Lin, W.Y.; Chang, P.C.; Lee, M.Y. On the design of an efficient cardiac health monitoring system through combined analysis of ECG and SCG signals. Sensors 2018, 18, 379. [CrossRef]

41. Javaid, A.Q.; Ashouri, H.; Dorier, A.; Etemadi, M.; Heller, J.A.; Roy, S.; Inan, O.T. Quantifying and reducing motion artifacts in wearable seismocardiogram measurements during walking to assess left ventricular health. IEEE Trans. Biomed. Eng. 2017, 64, 1277-1286. [CrossRef]

42. Pandia, K.; Ravindran, S.; Kovacs, G.T.A.; Giovangrandi, L.; Cole, R. Chest-accelerometry for hemodynamic trending during valsalvarecovery. In Proceedings of the 2010 3rd International Symposium on Applied Sciences in Biomedical and Communication Technologies, Rome, Italy, 7-10 November 2010; pp. 1-5.

43. Leonhardt, S.; Leicht, L.; Teichmann, D. Unobtrusive vital sign monitoring in automotive environments-A review. Sensors 2018, 18, 3080. [CrossRef]

44. Yang, C.; Tavassolian, N. Motion Noise Cansellation in Seismocardiographic Monitoring of Moving Subjects. In IEEE Biomedical Circuits and Systems Conferences (BioCAS); IEEE: Piscataway, NJ, USA, 2015.

45. Hurnanen, T.; Lehtonen, E.; Jafari Tadi, M.; Kuusela, T.; Kiviniemi, T.; Saraste, A.; Vasankari, T.; Airaksinen, J.; Koivisto, T.; Tadi, M.J.; et al. Automated Detection of Atrial Fibrillation Based on Time-Frequency Analysis of Seismocardiograms. IEEE J. Biomed. Health Inform. 2017, 21, 1233-1241. [CrossRef]

46. Mohammed, Z.; Elfadel, I.; Abe, M.; Rasras, M. Monolithic multi degree of freedom (MDoF) capacitive MEMS accelerometers. Micromachines 2018, 9, 602. [CrossRef]

47. Cooper, S.; Cant, R.; Sparkes, L. Respiratory rate records: The repeated rate? J. Clin. Nurs. 2014, 23, 1236-1238. [CrossRef]

48. Mizuno, N.; Washino, K. A model based filtering technique for driver's heart rate monitoring using seat-embedded vibration sensors. In ISCCSP 2014-2014 The 6th International Symposium on Communications, Control, and Signal Processing Proceedings; IEEE: Piscataway, NJ, USA, 2014. [CrossRef]

49. Holcik, J.; Moudr, J. Mathematical model of seismocardiogram. World Congr. Med. Phys. Biomed. 2007, 14, 3415-3418.

50. Casanella, R.; Inan, O.T.; Migeotte, P.; Park, K.; Member, S.; Etemadi, M.; Member, S.; Tavakolian, K.; Casanella, R.; Zanetti, J.; et al. Ballistocardiography and Seismocardiography: Ballistocardiography and Seismocardiography: A Review of Recent Advances. J. Biomed. Health Inform. 2014, 19, 1414-1427. [CrossRef]

51. Leitão, F.; Moreira, E.; Alves, F.; Lourenço, M.; Azevedo, O.; Gaspar, J.; Rocha, L.A. High-Resolution Seismocardiogram Acquisition and Analysis System. Sensors 2018, 18, 3441. [CrossRef]

52. Okada, S.; Fujiwara, Y.; Yasuda, M.; Ohno, Y.; Makikawa, M. Non-restrictive heart rate monitoring using an acceleration sensor. In Proceedings of the 2006 International Conference of the IEEE Engineering in Medicine and Biology Society, New York, NY, USA, 30 August-3 September 2006.

53. Jafari Tadi, M.; Lehtonen, E.; Saraste, A.; Tuominen, J.; Koskinen, J.; Teräs, M.; Airaksinen, J.; Pänkäälä, M.; Koivisto, T Gyrocardiography: A New Non-invasive Monitoring Method for the Assessment of Cardiac Mechanics and the Estimation of Hemodynamic Variables. Sci. Rep. 2017, 7, 6823. [CrossRef] 
54. Luu, L.; Dinh, A. Using Moving Average Method to Recognize Systole and Diastole on Seismocardiogram without ECG Signal. In Proceedings of the Annual International Conference of the IEEE Engineering in Medicine and Biology Society, EMBS, Honolulu, HI, USA, 18-21 July 2018; pp. 3796-3799.

55. Di Rienzo, M.; Vaini, E.; Lombardi, P. An algorithm for the beat-to-beat assessment of cardiac mechanics during sleep on Earth and in microgravity from the seismocardiogram. Sci. Rep. 2017, 7, 1-12. [CrossRef]

56. Shafiq, G.; Tatinati, S.; Ang, W.T.; Veluvolu, K.C. Automatic Identification of Systolic Time Intervals in Seismocardiogram. Sci. Rep. 2016, 6, 37524. [CrossRef]

57. Georgoulas, G.; Chudacek, V.; Rieger, J.; Stylios, C.; Lhotska, L. Methods and Tools for Prosessing Biosignals: A Survey Paper In Proceedings of the the 3rd European Medical \& Biological Engineering Conference, Prague, Czech Republic, 20-25 November 2005; Volume 11, pp. 20-25.

58. Fong, S.; Hang, Y.; Mohammed, S.; Fiaidhi, J. Stream-based Biomedical Classification Algorithms for Analyzing Biosignals. J. Inf. Process. Syst. 2012, 7, 717-732. [CrossRef]

59. Fong, S.; Lan, K.; Sun, P.; Mohammed, S.; Fiaidhi, J. A Time-Series Pre-Processing Methodology for Biosignal Classification using Statistical Feature Extraction. In Proceedings of the 10th IASTED International Conference on Biomedical Engineering (Biomed'13), Innsbruck, Austria, 13-15 February 2013; pp. 207-214.

60. Sircar, P. Mathematical Aspects of Signal Processing; Cambridge University Press: Cambridge, UK, 2016 ; ISBN 9781107175174.

61. Di Rienzo, M.; Meriggi, P.; Rizzo, F.; Vaini, E.; Faini, A.; Merati, G.; Parati, G.; Castiglioni, P. A wearable system for the seismocardiogram assessment in daily life conditions. In Proceedings of the 2011 Annual International Conference of the IEEE Engineering in Medicine and Biology Society, Boston, MA, USA, 30 August-3 September 2011; pp. 4263-4266.

62. Kaisti, M.; Tadi, M.J.; Lahdenoja, O.; Hurnanen, T.; Saraste, A.; Pankaala, M.; Koivisto, T. Stand-Alone Heartbeat Detection in Multidimensional Mechanocardiograms. IEEE Sens. J. 2019, 19, 234-242. [CrossRef]

63. Jafari Tadi, M.; Lehtonen, E.; Hurnanen, T.; Koskinen, J.; Eriksson, J.; Pänkäälä, M.; Teräs, M.; Koivisto, T. A real-time approach for heart rate monitoring using a Hilbert transform in seismocardiograms. Physiol. Meas. 2016, 37, 1885-1909. [CrossRef]

64. Semmlow, J.L.; Griffel, B. Biosignal and Medical Image Processing MATLAB-Based Application, 3rd ed.; Taylor \& Francis Group: New York, NY, USA, 2014; ISBN 9781466567368.

65. Poularikas, A.D. Discrete Random Signal Processing and Filtering Primer with MATLAB; Taylor \& Francis Group: New York, NY, USA, 2008; ISBN 9781420089332.

66. Sørensen, K.; Schmidt, S.E.; Jensen, A.S.; Søgaard, P.; Struijk, J.J. Definition of Fiducial Points in the Normal Seismocardiogram. Sci. Rep. 2018, 8, 15455. [CrossRef] [PubMed]

67. Mora, N.; Cocconcelli, F.; Matrella, G.; Ciampolini, P. Detection and Analysis of Heartbeats in Seismocardiogram Signals. Sensors 2020, 20, 1670. [CrossRef] [PubMed] 